\title{
PRODUÇÃO DO CONHECIMENTO EM LUTAS NO CURRÍCULO DA EDUCAÇÃO FÍSICA ESCOLAR
}

\author{
PRODUCTION OF KNOWLEDGE ABOUT WRESTLING IN THE SCHOOL \\ CURRICULUM OF PHYSICAL EDUCATION
}

PRODUCCIÓN DEL CONOCIMIENTO EN DEPORTES DE LUCHA EN EL CURRÍCULO DE LA EDUCACIÓN FÍSICA ESCOLAR

Marcio Antonio Raiol Santos*, Pedro Paulo Souza Brandão*

\section{Palavras chave: Educação. \\ Currículo. \\ Educação Física. Lutas.}

Keywords:

Education.

Curriculum.

Physical Education.

Wrestling.

\begin{abstract}
Resumo: Este artigo tem como objetivos: analisar a produção acadêmica sobre o conteúdo Lutas no currículo da Educação Física Escolar; apresentar um panorama das pesquisas na referida área; e investigar os processos didático-metodológicos do ensino das Lutas na Educação Física Escolar. Para atingi-los, nossa opção metodológica foi realizar um Estado da Arte da produção sobre a temática. Como resultado, apontamos que as Lutas, no contexto escolar, são um campo de pesquisa emergente. Uma série de fatores restringe a aplicação desse conteúdo na escola. Apesar de existirem várias propostas de sistematização do conhecimento das Lutas na Educação Física Escolar, não há vinculação destas com as abordagens pedagógicas da Educação Física, tampouco é apresentada uma metodologia de ensino própria para tal conhecimento, sendo a Pedagogia do Esporte o principal embasamento das propostas. Há, portanto, a necessidade de ampliar a produção do conhecimento nesta temática para subsidiar a prática dos professores na escola.
\end{abstract}

\begin{abstract}
This article analyzes the academic production on the content Wrestling in the curriculum of School Physical Education, presents an overview of research in the area and investigates didactic-methodological processes in teaching Wrestling in School Physical Education. We looked into the current status of production on the subject. We pointed out that Wrestling is an emerging field of research in the school context. Several factors restrict its application in schools. Although there are several proposals to systematize knowledge about Wrestling in Physical Education, they are not linked to pedagogical approaches in $\mathrm{PE}$, and there is no proper teaching methodology for such knowledge as Sports Pedagogy is the main basis of the proposals. Therefore, knowledge production in the area has to be expanded to support teachers' practice at school.
\end{abstract}

Palabras clave: Educación.

Currículo.

Educación Física. Luchas
Resumen: Este artículo tiene como objetivos: analizar la producción académica sobre el contenido de deportes de Lucha en el currículo de la Educación Física escolar; presentar un panorama de las investigaciones en el área e investigar los procesos didácticometodológicos de la enseñanza de deportes de lucha en la Educación Física escolar. Para alcanzar estos propósitos, nuestra opción metodológica fue realizar un Estado del Arte de la producción sobre el tema. Como resultados, señalamos que los deportes de lucha, en el contexto escolar, son un campo de investigación emergente. Una serie de factores restringe la aplicación de ese contenido en la escuela. A pesar de que existen varias propuestas de sistematización del conocimiento de los deportes de lucha en la Educación Física escolar, éstas no se vinculan con las aproximaciones pedagógicas de la Educación Física, tampoco se presenta una metodología de enseñanza propia para tal conocimiento, siendo la Pedagogía del Deporte el principal fundamento de las propuestas. Existe, por lo tanto, la necesidad de ampliar la producción de conocimiento en esta temática para dar soporte a la práctica de los profesores en la escuela...
*Universidade Federal do Pará. Belém, PA, Brasil.

E-mail: marsraiol@gmail.com; mars@ufpa.br

Recebido em: 20-11-2017 Aprovado em: 19-02-2019 Publicado em: 02-05-2019

DOI: https://doi.org/10.22456/1982-8918.78143

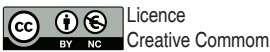




\section{INTRODUÇÃO}

As Lutas têm suas origens mais antigas na pré-história. Antes mesmo de a humanidade dominar a fala e a escrita, as Lutas já eram práticas utilitárias da sociedade, seja em confrontos por território, seja por sobrevivência, conforme representação em alguns registros rupestres (PAIVA, 2015).

$\mathrm{Na}$ antiguidade os registros mais antigos datam de 5000 a.C., nos territórios onde hoje se encontram a Índia e a China. Foi no Oriente também que essas práticas sofreram os primeiros processos de sistematização, assumindo o caráter educativo e filosófico adotado pelos guerreiros, como um modo de vida transformado, posteriormente, em sistema de treinamentos para a guerra.

A partir do século XVI, com a descoberta da pólvora e o desenvolvimento das armas de fogo, as Lutas corporais perderam importância nas instituições militares, no entanto, com o advento do Esporte, no contexto pós-Revolução Industrial, as Lutas aos poucos foram sendo apropriadas e sistematizadas como práticas desportivas, o que fez com que muitos princípios filosóficos e seus significados de origem se perdessem.

Apesar disso, as Lutas permaneceram como construção histórica e social da humanidade e logo foram incorporadas ao rol de conhecimentos que compõem a cultura corporal, com isso, foram ganhando espaço nos currículos escolares por meio da disciplina Educação Física.

No Brasil, durante a década de 1990, os Parâmetros Curriculares Nacionais (PCNs) (BRASIL, 1997) foram os primeiros documentos oficiais a apresentar as Lutas como componentes do currículo da Educação Física Escolar. Passados 20 anos da implementação dos PCNs, um novo documento referenda as Lutas como integrante do currículo da Educação Física Escolar, a Base Nacional Comum Curricular-BNCC (BRASIL, 2017). Ainda assim, Betti, Ferraz e Dantas (2011) apontam que 6,1\% da produção do conhecimento nos conteúdos da Educação Física são da área de Lutas, o que é ratificado por Cintra et al., (2016) ao relatarem o pouco aporte teórico sobre esse conhecimento nas escolas.

Diante deste fato, os objetivos deste estudo são: analisar a produção acadêmica sobre o conteúdo Lutas no currículo da Educação Física Escolar, apresentar um panorama das pesquisas na referida área; e investigar os processos didático-metodológicos do ensino das Lutas na Educação Física Escolar.

Para atingir esses objetivos, os resultados de nossa pesquisa foram estruturados em duas seções: na primeira, "Panorama da produção do conhecimento em Lutas na Educação Física Escolar", apresentamos o cenário atual das pesquisas sobre a temática na Educação Física Escolar e as principais preocupações da produção existente, classificando-as em categorias.

A segunda seção, "Os processos didático-metodológicos do ensino das Lutas na Educação Básica: o que dizem as pesquisas?", discute a principal categoria encontrada no levantamento, referente à prática pedagógica, na qual analisamos os fatores restritivos e dificuldades na aplicação do conhecimento das Lutas na Educação Básica e as propostas de sistematização das Lutas e possibilidades no currículo da Educação Física Escolar. 


\section{METODOLOGIA}

Esta pesquisa é um Estado da Arte, que é classificado como uma pesquisa inventariante que tem como objetivo conhecer o que já se produziu sobre determinado assunto para analisar o fenômeno e apontar suas lacunas e avanços (FERREIRA, 2002).

Optamos por trabalhar com teses e dissertações produzidas nas áreas de avaliação e concentração da Capes denominadas Educação e Educação Física, respectivamente; e artigos em periódicos produzidos no campo da Educação Física.

O Banco de Teses e Dissertações da Capes foi escolhido como fonte de coleta dos documentos dessa natureza, o que delimitou o recorte temporal desta pesquisa, a partir do ano de 2002, ano de criação do referido banco de dados. Porém, no referido banco de dados, estão disponíveis pesquisas datadas de 1987.

Definimos como critérios de busca e seleção a acessibilidade online éreas de avaliação e concentração Educação e Educação Física, marcadas na barra de refinamento do banco de dados. Como descritores principais escolhemos as palavras "Lutas", "Lutas corporais", "artes marciais", "arte de combate" e "Educação Física Escolar" associadas aos termos "currículo", "currículo da Educação Física" pelo operador Booleano "AND" para refinar a pesquisa. Esses descritores deveriam estar presentes no título, palavras-chave e/ou resumo dos documentos.

A partir desses critérios, obtivemos os resultados mostrados no Quadro 1:

Quadro 1- Resultado da busca com os descritores.

\begin{tabular}{|l|c|}
\hline Descritores & Número de documentos \\
\hline "Lutas" & 4229 \\
\hline "Lutas corporais" & 6 \\
\hline "Artes marciais" & 115 \\
\hline "Artes de combate" & 0 \\
\hline "Lutas" AND "Currículo" & 148 \\
\hline "Lutas" AND "Educação Física Escolar" & 123 \\
\hline "Lutas" AND "Currículo da Educação Física" & 1 \\
\hline
\end{tabular}

Fonte: Autores do artigo.

A partir da busca realizada com tais descritores, selecionamos os documentos a analisar pelo critério do segundo descritor. A seleção deu-se a partir da identificação e leitura dos títulos e resumos das obras, buscando filtrar os documentos relacionados ao nosso objeto. Dessa forma obtivemos um total de oito documentos, sendo seis dissertações e duas teses.

Com a utilização dos mesmos descritores, os artigos foram encontrados em periódicos nacionais da área da Educação Física classificados de "A" a "C" no sistema Qualis Capes, de natureza tanto generalista quanto profissional e acadêmica, tendo como resultado um total de 465 periódicos. Os critérios para filtragem dos periódicos foram: 1- acessibilidade online; 2- apresentar-se no campo da Educação Física em sua política editorial ou escopo; 3- periodicidade de no mínimo cinco anos.

Dentre as revistas identificadas, 187 obedeciam ao primeiro critério, restringidas a 27 quando enquadradas no segundo critério; e, finalmente, reduzidas ao número final de 13 revistas, quando aplicadas ao terceiro critério. 
O recorte temporal foi delimitado de acordo com a data de criação do banco de dados online de cada periódico, sendo assim, foram encontrados 18 artigos, excluindo-se aqueles enquadrados na perspectiva do alto rendimento e em ambientes não escolares. Isto posto, os artigos encontrados somam-se às oito teses e dissertações, formando um total de 26 documentos.

Os documentos foram analisados a partir da técnica da Análise de Conteúdo (BARDIN, 1977), realizada a partir da leitura das obras, assim os documentos foram classificados nas seguintes categorias: 1- Formação de professores: pesquisas que envolvem o conhecimento das Lutas no processo de formação dos professores de Educação Física; 2- Epistemologia das Lutas: estudos sobre a natureza das Lutas como conhecimento da Educação Física; 3Práticas pedagógicas: pesquisas sobre os processos didático-metodológicos do ensino das Lutas na Educação Básica; 4- Lutas e Currículo: estudos que discutem a interface das Lutas no currículo escolar.

A categoria "práticas pedagógicas" foi desmembrada em subcategorias para uma nova análise, pois a nossa leitura do objeto se dá na perspectiva do trato com o conhecimento das Lutas no currículo da Educação Básica, dessa forma, as subcategorias analisadas foram: 1-Fatores restritivos e fragilidades no trato do conhecimento; 2- Propostas de sistematização do conhecimento no currículo da Educação Básica.

A partir das análises, a última etapa se caracterizou pela realização de inferências sobre o objeto, que serão apresentadas neste trabalho.

\section{PANORAMA DA PRODUÇÃO DO CONHECIMENTO EM LUTAS NA EDUCAÇÃO FÍSICA ESCOLAR}

O levantamento realizado revelou que a produção sobre o conteúdo Lutas nas práticas de Educação Física ainda encontra-se em estágio inicial; revelou, também, que o interesse de pesquisadores por tal temática ainda é recente, pois teve suas primeiras publicações nos últimos dez anos, sendo a obra de Nascimento e Almeida (2007) a publicação mais antiga encontrada, no universo de teses e dissertações. No que tange aos artigos, o número de publicações é ainda menor, sendo a primeira publicação de documentos dessa natureza datada do ano de 2008, por Gomes (2008); o que coloca as Lutas como um campo de pesquisa emergente, como podemos observar na Tabela 1:

Tabela 1- Levantamento da produção sobre Lutas na Educação Física Escolar.

\begin{tabular}{lccccccccccc}
\hline Documentos/ano & $\mathbf{2 0 0 7}$ & $\mathbf{2 0 0 8}$ & $\mathbf{2 0 0 9}$ & $\mathbf{2 0 1 0}$ & $\mathbf{2 0 1 1}$ & $\mathbf{2 0 1 2}$ & $\mathbf{2 0 1 3}$ & $\mathbf{2 0 1 4}$ & $\mathbf{2 0 1 5}$ & $\mathbf{2 0 1 6}$ & $\mathbf{2 0 1 7}$ \\
\hline Artigos de periódicos & 1 & 1 & 0 & 1 & 2 & 1 & 4 & 1 & 6 & 0 & 1 \\
Dissertações & 0 & 1 & 0 & 0 & 0 & 2 & 1 & 1 & 0 & 1 & 0 \\
Teses & 0 & 0 & 0 & 0 & 0 & 0 & 0 & 1 & 1 & 0 & 0 \\
\hline Total & 1 & 2 & 0 & 1 & 2 & 3 & 5 & 3 & 7 & 1 & 1 \\
\hline \multicolumn{7}{c}{ Fonte: Autores do artigo. }
\end{tabular}

O quadro explicita que, após a primeira publicação, não houve um interesse significativo por parte de pesquisadores em produzir sobre essa temática, existindo grande oscilação na publicação de artigos e pouco movimento na produção de teses e dissertações (duas e seis, respectivamente), com grande diferença de espaço da primeira publicação para as outras. 
Em geral, nos anos de 2013 e 2015 foram encontrados o maior número de publicações. Em contrapartida, apenas em 2014 e 2015 houve publicações dos três tipos de documentos.

O desinteresse de pesquisadores sobre a temática das Lutas demonstra a fragilidade de aporte teórico sobre esse conhecimento no âmbito escolar, mesmo depois da implantação dos Parâmetros Curriculares Nacionais (1997) que apresentaram oficialmente as Lutas como conteúdo da Educação Física Escolar, chegando aos dias atuais com a Base Nacional Comum Curricular, em suas três versões (2015, 2016 e 2017). Verificamos que a produção não cresceu, existindo, portanto, uma lacuna latente entre as obras.

Betti, Ferraz e Dantas (2011) já apontavam para a pouca produção sobre Lutas no que se refere aos conhecimentos da Educação Física Escolar. As constatações dos autores reforçam nosso interesse na compreensão e na produção do conhecimento sobre o ensino de Lutas no campo da Educação Física.

Organizamos as obras de acordo com a categoria na qual se enquadravam. Cada categoria reflete uma problemática principal, apontada pelos autores, referente ao conhecimento das Lutas, com isso, obtivemos os seguintes resultados sobre o panorama das discussões:

Tabela 2- Produção classificada por categoria.

\begin{tabular}{lc}
\hline Categorias & Número de publicações \\
\hline Prática pedagógica & 15 \\
Epistemologia das Lutas & 6 \\
Formação de professores & 3 \\
Lutas e Currículo & 2 \\
\hline
\end{tabular}

Fonte: Autores do artigo.

Como vemos, a Tabela 2 demonstra que a preocupação da maioria das pesquisas mapeadas é com a prática pedagógica, totalizando metade da produção mapeada, ou seja, 15 documentos. A segunda maior categoria é a de epistemologia das Lutas, a primeira publicação encontrada sobre esta categoria foi a de Gomes et al., (2010), que teve como objetivo identificar princípios comuns para o ensino das Lutas. Tais princípios possibilitam caracterizar as Lutas como prática específica, o que nos leva a constatar que, apesar de quase duas décadas da consolidação das Lutas como conteúdo da Educação Física por meio dos Parâmetros Curriculares Nacionais, percebemos que os poucos pesquisadores que se interessam pela temática ainda estão tentando compreender o que de fato são as Lutas e o que as torna um conhecimento peculiar.

Rufino e Darido (2011) questionam as diferenças entre Lutas e esportes, e o que seria de tão contundente para que as Lutas, antes classificadas como componentes do Esporte, possam ser separadas em um conteúdo específico. Os autores evidenciam que a separação entre os dois conteúdos, justificada pelas concepções diferentes que têm, poderia garantir que as Lutas fossem de fato implementadas nas aulas de Educação Física na escola básica.

Em estudos mais recentes, Correia (2015) e Carneiro, Picoli e Santos (2015) propõem uma discussão dos conceitos de Lutas não apenas a partir das modalidades esportivas, mas das artes marciais. $O$ primeiro objetivou analisar as concepções que a Educação Física atribui às Lutas como conhecimento da Educação Física, portanto como conteúdo integrante do 
currículo da escola básica; o segundo levanta a proposição de aprimoramento do conceito a partir de bases filosóficas, ontológicas e epistemológicas, problematizando os limites conceituais existentes.

A nosso ver, a solidificação das Lutas como conhecimento específico necessita não somente da determinação de características específicas, mas de concordância conceitual por parte da comunidade científica. Essa problematização foi efetuada na dissertação de Gonçalves (2012). O autor salienta as principais discussões que permeiam as Lutas como saber científico da Educação Física.

A incompreensão desses elementos pode ser uma das causas pelas quais as pesquisas no campo da Educação Física são indiferentes quanto a esse conhecimento. Como apontou o levantamento realizado, a busca por essa compreensão reflete-se na apresentação da Tabela 2, por ser a segunda categoria constante do maior número de trabalhos produzidos.

A formação de professores vem logo em seguida, com três publicações, demonstrando que esta não é prioridade nos estudos sobre o conhecimento das Lutas, com destaque para a tese de Gomes (2014), que foi a primeira produzida recentemente.

Podemos inferir que os problemas encontrados para a sistematização do conhecimento e o próprio trato pedagógico das Lutas na formação são um reflexo de uma formação fragilizada como um todo, a começar pela forma como as disciplinas que conversam com esse conhecimento são conduzidas na Universidade, sendo oferecidas de forma eletiva ou de forma fragmentada, como constatam Mendonça et al., (2012) e Brandão (2015), o que pode interferir diretamente no interesse dos professores em utilizar ou não as Lutas na Educação Básica, pois o domínio do conhecimento e de suas ferramentas para aplicação é fundamental para que isso se concretize.

Apesar das discussões sobre formação de professores estarem atreladas ao currículo, poucas foram as pesquisas que se debruçaram sobre as Lutas no currículo da Educação Física Escolar. Encontramos apenas Oliveira (2016) e Matos et al., (2015), o que fez, conseguinte, da categoria "Lutas e Currículo" a menos recorrente no corpus analisado.

Podemos notar que são duas pesquisas muito recentes, produzidas nos três últimos anos, o que reforça nosso argumento sobre atualidade da preocupação com as Lutas no currículo, pois tal preocupação não foi detectada em anos anteriores. Os autores mais uma vez deixam clara a necessidade de qualificar a formação de professores, tanto inicial quanto continuada, pois ela tem o papel de fornecer aos professores os subsídios para sua intervenção pedagógica. Em virtude dessa problemática, os autores apontam que os princípios comuns das Lutas e todas as suas peculiaridades sejam o foco principal da formação dos professores, para que estes levem para o chão da escola um conjunto de ferramentas que possibilitem uma melhor aplicação desse conteúdo, dada a ausência ou pouca presença desse elemento da cultura corporal no currículo da escola básica, como demonstram os estudos de Matos et al. (2015).

Oliveira (2016) identifica a existência de uma diferença entre o conhecimento de Lutas que os professores levam para a escola e o que realmente deveriam levar, refletindo a falta de domínio deste saber, por parte dos professores.

As constatações do levantamento realizado confirmam o que Betti, Ferraz e Dantas (2011) afirmam: as Lutas, como objeto de investigação de pesquisas na área escolar, 
representam apenas $6,1 \%$ da produção, sendo o Jogo o conteúdo de maior frequência nas pesquisas $(40,2 \%)$, comprovando a disparidade que existe entre a produção do conhecimento na temática das Lutas e a de outros conteúdos da Educação Física.

Cintra et al. (2016) confirmam a falta de interesse pela temática ao encontrar apenas 20 artigos em seu levantamento. Mesmo ampliando a busca para outras bases de dados e periódicos não indexados, os próprios autores constatam e afirmam essa falta de interesse e a fragilidade de aporte teórico sobre o tema. Essa falta de interesse gera as problemáticas encontradas nos resultados das pesquisas em cada categoria, todas interligadas em círculo contínuo como as fragilidades na formação de professores, que acabam implicando negativamente na inserção das Lutas no currículo real da Educação Física Escolar.

Essa inserção sofre ainda as consequências do aporte teórico-científico escasso, como foi apontado na categoria epistemologia das Lutas. Ainda pouco se compreende sobre os conceitos e princípios comuns das Lutas, havendo divergências conceituais entre os autores, fato que advém da pouca produção sobre a temática no campo escolar, sendo a maioria dos trabalhos dessa pouca produção voltada para a área não escolar (CINTRA et al., 2016).

Apontamos como primordial para as mudanças no cenário apresentado a necessidade de mais estudos longitudinais para contemplar todas as categorias mencionadas, pois, apesar de a maioria das pesquisas selecionadas contemplarem os processos didático-metodológicos do ensino das Lutas, na Educação Física Escolar, é necessário que as dificuldades que se originam na formação de professores e na compreensão dos aspectos epistemológicos sejam sanadas, o que consequentemente aumentaria o interesse e a produção na temática das Lutas.

A seguir iremos problematizar os estudos referentes aos processos didáticometodológicos do ensino das Lutas na Educação Física Escolar, analisando os 15 documentos encontrados no levantamento a fim de discutir o que dizem os autores sobre a prática pedagógica no campo das Lutas e as possíveis lacunas que devem ser superadas, assim como nas categorias que já foram mencionadas.

\section{OS PROCESSOS DIDÁTICO-METODOLÓGICOS DO ENSINO DAS LUTAS NA EDUCAÇÃO BÁSICA: $O$ QUE DIZEM AS PESQUISAS?}

Nesta seção apresentaremos o que dizem as teses, dissertações e artigos sobre os procedimentos didático-metodológicos do ensino das Lutas na Educação Básica. Em se tratando do universo das produções selecionadas, a Tabela 3 demonstra a distribuição dessa produção nas duas subcategorias criadas:

Tabela 3 - Número de documentos por subcategoria.

\begin{tabular}{lc}
\hline Subcategorias & Número de \\
& publicações \\
\hline Propostas de sistematização do conhecimento das Lutas e possibilidades de & 10 \\
inserção no currículo da Educação Básica. & 5 \\
Fatores restritivos e fragilidades no trato com o conhecimento. & 15 \\
\hline Total & \\
\hline
\end{tabular}


A Tabela 3 demonstra que dois terços dos trabalhos sobre prática pedagógica ocupam-se da apresentação de possibilidades de inserção das Lutas como conhecimento da Educação Física Escolar, propondo procedimentos didático-metodológicos, sistematização do conhecimento no currículo ou ideias para aderência das escolas e de seu público a esse conteúdo. Enquanto isso, um terço se detém a expor e problematizar os fatores restritivos e as dificuldades que existem para implementar as Lutas na escola básica.

Na subcategoria "Fatores restritivos e fragilidades no trato do conhecimento", o fator que aparece com maior frequência para a restrição do conteúdo das Lutas na Educação Física Escolar é a falta de domínio do conteúdo pelo docente, consequência de fragilidades durante a formação inicial e continuada, como comprova a pesquisa de Fonseca, Franchini e Del Vecchio (2013).

Como segundo fator mais recorrente nas pesquisas mencionadas encontra-se o receio da violência, que, na visão das pessoas, está atrelada à prática das Lutas, e que levar essas práticas para a escola fomentaria, ainda mais, a violência no espaço escolar. No entanto, é papel do próprio professor esclarecer aos alunos e à comunidade escolar e desconstruir tais equívocos, como corrobora Só (2014).

A falta de infraestrutura das escolas e a ausência de material para o trabalho com as práticas corporais de Lutas surgem como causas prejudiciais para o ensino deste conteúdo nas aulas de Educação Física, o que pode até ser verdadeiro, no entanto, este obstáculo não é exclusivo do conteúdo Lutas, mas uma realidade para se trabalhar qualquer temática na escola básica, em qualquer disciplina do currículo, pois faltam, dentre tantas deficiências estruturais, livros didáticos, laboratórios, salas de aula adequadas, entre outros problemas que fazem parte da realidade da escola pública brasileira, lócus de pesquisa das produções encontradas.

Outros fatores restritivos encontrados com menor incidência, mas de grande pertinência para a discussão, foram a carga horária reduzida da Educação Física Escolar e a hegemonia dos outros conteúdos (principalmente o Esporte) nas aulas desta disciplina. O Esporte acaba sendo o principal conteúdo das aulas e isto tem uma raiz histórica muito forte na Educação Física, que advém da década de 1970.

Tais fatores restritivos levaram à produção de pesquisas que se propunham a superar obstáculos para a implantação do conteúdo das Lutas na escola básica, não apenas oficialmente, como já acontecia desde a criação dos Parâmetros Curriculares Nacionais e, atualmente, nas três versões da Base Nacional Comum Curricular, mas que de fato fosse um conteúdo colocado em prática pelos professores. Inserimos essas pesquisas na categoria denominada "Propostas de sistematização do conhecimento das Lutas e Possibilidades de inserção no currículo da Educação Básica".

O primeiro fator comum a todas as propostas é a aplicação do Jogo, que é outro conteúdo da Educação Física, como ferramenta para iniciar o trato metodológico com as Lutas na Educação Básica. Gomes et al. (2013), Chaves, Silva e Medeiros (2014) e Maduro (2015) afirmam que os jogos pré-desportivos são os mais indicados para iniciação do conteúdo Lutas pelo seu menor grau de complexidade.

Nascimento (2008) e Maldonado e Bocchini (2013) sinalizam para a iniciação com os jogos de oposição, pelo fato desta ser uma das principais características das Lutas. 0 que podemos perceber é que esses autores buscam uma aproximação maior do Jogo com o que 
é a Luta em si, enquanto que os que utilizam os jogos pré-desportivos caminham em uma perspectiva das Lutas em uma abordagem desportiva.

As propostas de Lopes e Kerr (2015), Gomes et al., (2013), Chaves, Silva e Medeiros (2014), Rufino e Darido (2013), Maldonado e Bocchini (2013) compõem a maioria dos trabalhos, todas com base no modelo das dimensões dos conteúdos criado por Cesar Coll (1996). Esse modelo consiste em classificar os conteúdos em três dimensões que estão entrelaçadas: conceitual, procedimental e atitudinal. Não podem ser trabalhadas, portanto, isoladamente.

Os demais trabalhos seguem propostas diferentes, tais como: Nascimento (2008), Maduro (2015), Lima Junior e Chaves Junior (2011) e Gomes (2008). Estes autores apresentam divergências entre si, mas concordam em alguns itens de suas abordagens, apresentados a seguir.

Maduro (2015) e Gomes (2008) afluem para um ensino que tenha seu ponto de partida nos aspectos comuns e cheguem até as características mais complexas das Lutas. No entanto, Maduro (2015) sugere que as atividades de cooperação sejam as primeiras a serem ensinadas e, posteriormente, os aspectos de oposição sejam introduzidos.

Gomes (2008) coloca os princípios condicionais no centro do processo, pois a partir destes se iniciará o ensino para que os educandos compreendam a dinâmica das Lutas. Este é o principal objetivo da etapa inicial de um ensino global das Lutas para a autora. Outro ponto de concordância entre pesquisas é entre Chaves, Silva e Medeiros (2014), Lima Junior e Chaves Junior (2011) e Maldonado e Bocchini (2013), ao concordarem que os vídeos podem ser excelentes instrumentos didáticos para o trabalho com o conteúdo das Lutas, podendo ser uma técnica empregada para a exibição de filmes e documentários sobre Lutas.

Em se tratando das peculiaridades das propostas, Nascimento (2008) elaborou uma para os anos iniciais e outra para os anos finais do ensino fundamental. Para os anos iniciais, 0 autor dividiu os objetivos em duas etapas: na primeira, o elemento comum às Lutas seria o foco, com atividades que desenvolvam habilidades motoras básicas; na segunda, uma tematização das Lutas como construção humana e a lógica de sua estrutura.

Para os anos finais, a pesquisa apresenta um caráter vivencial no qual os elementos técnicos e táticos de Lutas específicas selecionadas pelo autor: Capoeira, Karatê e Judô, são aplicados.

Já Gomes et al. (2013) pensou uma organização curricular para as séries iniciais do ensino fundamental. Essa proposta acredita no Jogo como ferramenta que possibilita 0 aprendizado dos elementos principais das Lutas, e classifica estes jogos como de: esquivar, imobilizar, conquistar território e desequilibrar.

As propostas de Nascimento (2008) e Gomes et al. (2013) apresentam aproximações no que tange aos conteúdos como os jogos de ataque e defesa e os jogos de desequilibrar, imobilizar e esquivar, todavia algumas diferenças são percebidas, pois Gomes et al. (2013) sugerem 0 ensino de elementos técnico-táticos no $5^{\circ}$ ano do ensino fundamental, enquanto Nascimento (2008) alega que estes elementos só devem ser inseridos a partir dos anos finais. Da mesma forma, a discussão conceitual das diferenças entre Luta e briga devem ser abordadas nos anos finais para Nascimento (2008), o que Gomes et al. (2013) apontam já para o primeiro ano dos anos iniciais. 
Chaves, Silva e Medeiros (2014) atentam para os temas transversais como possibilidades para 0 trato com as Lutas, a exemplo dos conhecimentos sobre o corpo, sinalizados nos Parâmetros Curriculares Nacionais ou temas especiais como denomina a Base Nacional Comum Curricular. Para esses autores, os espaços para os temas especiais existem, visto que, as habilidades motoras e os gestos técnicos não serão o foco principal do ensino das Lutas na escola.

As possibilidades eleitas por Lima Junior e Chaves Junior (2011) e Maldonado e Bocchini (2013) nos causam preocupação, pois, enquanto autores como Gomes (2008) defendem um ensino global das Lutas que consideramos mais apropriado para a formação dos educandos na Educação Física Escolar, essas duas pesquisas apresentam propostas de fragmentação do conteúdo em modalidades, dando ênfase a elas.

Gomes (2008), por sua vez, traz uma proposta que dá ênfase ao ensino global das Lutas e ao professor de Educação Física, que não precisa ser especialista para tratar o conteúdo na escola, baseada na Pedagogia do Esporte. É com base no ensino global das Lutas que acreditamos ser possível a sistematização desse conhecimento na escola básica.

\section{CONSIDERAÇÕES FINAIS}

Com base no que foi exposto, constatamos que a produção sobre o conhecimento das Lutas ainda é recente na Educação Física Escolar, apesar de ser uma construção antiga da história da humanidade. $O$ artigo demonstra que este conhecimento é uma temática emergente, com potencial para pesquisas futuras.

Identificamos que a principal preocupação da produção na temática dá-se no campo das práticas pedagógicas, portanto a produção de conhecimento existente sobre ensino de Lutas na escola básica interessa aos pesquisadores que desejam atender a demanda dos professores que anseiam por apropriação metodológica do conhecimento das Lutas.

Entre essas pesquisas percebemos que, apesar de algumas tratarem dos fatores restritivos que implicam a ausência do conteúdo na Educação Física Escolar, a maioria tem interesse em elaborar propostas para sistematização desse conhecimento.

Quanto às propostas apresentadas, o maior número delas relata a possibilidade em torno das dimensões dos conteúdos com tematização das Lutas e expõe suas bases teóricas para a proposição de uma pedagogia das Lutas, as outras propostas centram suas perspectivas nos procedimentos e na forma como serão executados, no entanto, percebemos que as propostas existentes não demonstram nenhuma vinculação com as abordagens didático-pedagógicas mais difundidas no campo da Educação Física, constituindo-se em uma discussão isolada dos outros conhecimentos (conteúdos) tratados na Educação Física Escolar.

Apontamos como primordial, para as mudanças no cenário apresentado, a necessidade de mais estudos longitudinais para contemplar todas as categorias mencionadas. Apesar de a maioria das pesquisas selecionadas contemplar os processos didático-metodológicos do ensino das Lutas na Educação Física Escolar, é necessário que as dificuldades que se originam na formação de professores e na compreensão dos aspectos epistemológicos sejam sanadas, o que consequentemente contribuiria para o aumento da produção na temática das Lutas e 0 avanço nas propostas para o trato do conhecimento deste conteúdo nas aulas de 
Educação Física Escolar. Assim, a elaboração de possibilidades metodológicas perpassa pelo conhecimento da interface do conteúdo das Lutas com o currículo da Educação Física na escola básica.

\section{REFERÊNCIAS}

BARDIN, Laurence. Análise de conteúdo. Lisboa: Edições 70, 1977.

BETTI, Mauro; FERRAZ, Osvaldo Luiz; DANTAS, Luiz Eduardo Pinto Bastos Tourinho. Educação Física Escolar: estado da arte e direções futuras. Revista Brasileira de Educação Física e Esporte, v.25, n. esp., p.105-115, dez. 2011.

BRANDÃO, Pedro P.S. Ensino das Lutas: Formação do professor e aplicação pedagógica. 2015. 28 f. Monografia (Especialização em Pedagogia da Cultura Corporal) - Universidade do Estado do Pará, Belém, 2015.

BRASIL. Secretaria de Educação Fundamental. Parâmetros Curriculares Nacionais: introdução aos parâmetros curriculares nacionais. Brasília, DF: MEC/SEF, 1997.

BRASIL. Ministério da Educação. Secretaria da Educação Básica. Base Nacional Comum Curricular. Brasília-DF: CONSED: UNDIME, 2017.

CARNEIRO, Felipe Ferreira Barros; PICOLI, Carlos; SANTOS, Wagner dos. Fundamentos ontológicos e epistemológicos das lutas corporais. Pensar a Prática, v.18, n.3, p. 725- 738, jul./ set. 2015.

CHAVES, Paula Nunes; SILVA, Ivana Lucia da; MEDEIROS, Rosie Marie Nascimento de. Lutas na Educação Física escolar: uma experiência no ensino médio. Cadernos de formação RBCE, v.2, n.5, p. 80-91, set. 2014.

CINTRA, Marina Melo; LEMOS, Marina de Paiva; CAMPOS; Luiz Antonio Silva; SIMÕES, Regina. O ensino das Lutas na Educação Física escolar: $O$ estado da arte. Coleção Pesquisa em Educação Física, v.15, n.1, p.127-134, 2016.

COLL, César. Psicologia e Currículo: uma aproximação psicopedagógica à elaboração do currículo escolar. São Paulo: Ática, 1996.

CORREIA, Walter Roberto. Educação Física Escolar e Artes Marciais: entre o combate e 0 debate. Revista Brasileira de Educação Física e Esporte, v.29, n.2, p.337-344, abr./jun. 2015.

FERREIRA, Norma Sandra. As pesquisas denominadas "estado da arte". Educação \&

Sociedade, v. 23, n. 79, 2002. Disponível em: http://www.scielo.br/pdf/es/v23n79/10857.pdf. Acesso em: 18 de ago. 2018.

FONSECA, Joel Maurício Corrêa; FRANCHINI, Emerson; DEL VECCHIO, Fabrício Boscolo. Conhecimento declarativo de docentes sobre a prática de lutas, artes marciais e modalidades esportivas de combate nas aulas de Educação Física escolar em Pelotas, Rio Grande do Sul. Pensar a prática, v.16, n.2, p.416-434, abr.jun. 2013. 
GOMES, Mariana Simões Pimentel. Procedimentos pedagógicos para o ensino das

Lutas: contextos e possibilidades. 2008. 119 f. Dissertação (Mestrado em Educação Física) Universidade Estadual de Campinas, Campinas, 2008.

GOMES, Mariana Simões Pimentel. 0 ensino do saber lutar na universidade: estudo da didática clínica nas lutas e esportes de combate. 2014. 205f. Tese (Doutorado em Educação Física) - Universidade Estadual de Campinas, Campinas, 2014.

GOMES, Mariana Simões Pimentel; MORATO, Marcio Pereira; DUARTE, Edison; ALMEIDA, José Júlio Gavião de. Ensino das Lutas: dos princípios condicionais aos grupos situacionais. Movimento, v.16, n.2, p.207-227, abr./jun. 2010.

GOMES, Nathalia Chaves. BARROS, André Minuzzo de. FREITAS, Fernando Paulo Rosa de. DARIDO, Suraya Cristina. RUFINO, Luiz Gustavo Bonatto. O conteúdo das lutas nas séries iniciais do ensino fundamental: possibilidades para a prática pedagógica da Educação Física Escolar. Motrivivência, v.25, n. 41, p. 305-320, dez. 2013.

GONÇALVES, Arisson Vinicius Landgraf. As práticas corporais de lutas pela ordem do Discurso científico da Educação Física. 2012. 65f. Dissertação (Mestrado em Educação em Ciências: química da vida e saúde) - Universidade Federal do Rio Grande, Rio Grande, 2012.

LIMA JUNIOR, Hamilton Carlos; CHAVES JUNIOR, Sergio Roberto. Possibilidades das lutas como conteúdo na educação física escolar: o confrontamento em uma abordagem pedagógica com alunos de 6a série em um colégio estadual do município de Guarapuava-PR. Cadernos de formação RBCE, v.2, n.1, p.69-80, jan. 2011.

LOPES, Raphael Gregory Bazílio; KERR, Tiemi Okimura. O ensino das lutas na Educação Física escolar: uma experiência no ensino fundamental. Motrivivência, v.27, n.45, p.262-279, set. 2015.

MADURO, Luiz Alcides. Considerações e sugestões para o ensino das lutas no ambiente escolar. Cadernos de formação RBCE, v.6, n.2, p. 101- 112, set. 2015.

MALDONADO, Daniel Teixeira; BOCCHINI, Daniel. As três dimensões do conteúdo na Educação Física: tematizando as lutas na escola pública. Conexões, v.11, n.4, p.195-211, out./ dez. 2013.

MATOS, José Arlen Beltrão de; HIRAMA, Leopoldo Katsuki; GALATTI, Larissa Rafaela; MONTAGNER, Paulo Cesar. A presença/ausência do conteúdo lutas na Educação Física escolar: identificando desafios e propondo sugestões. Conexões, v.13, n.2, p.117-135, abr./jun. 2015.

MENDONÇA, Giuliano P. A.; COSSOTE, Douglas F.; FERREIRA JUNIOR, O. N.; RODRIGUES, G. M. A Abordagem Pedagógica do conteúdo de Lutas em Curso de Licenciatura em Educação Física nas Instituições de Ensino Superior (IES). Pulsar, v. 4, n.1, p. 1-11, 2012.

NASCIMENTO, Paulo R. B; ALMEIDA, Luciano. A tematização das lutas na Educação Física Escolar: restrições e possibilidades. Movimento, v. 13, n. 3, p. 91-110, set./dez. 2007.

NASCIMENTO, Paulo R. B. Organização e Trato Pedagógico do Conteúdo de Lutas na Educação Física escolar. Motrivivência, v. 20, n. 31, p.36-49, dez. 2008.

OLIVEIRA, Lázaro Rocha. Artes marciais e Educação Física escolar: por articulações concretas possíveis no ensino. 2016. 87f. Dissertação (Mestrado em Ciências) -Universidade de 
PAIVA, Leandro. Olhar clínico nas Lutas, artes marciais e modalidades de combate.

Manaus: OMP, 2015.

RUFINO, Luiz Gustavo Bonatto; DARIDO, Suraya Cristina. A separação dos conteúdos das "lutas" dos "esportes" na educação física escolar: necessidade ou tradição? Pensar a Prática, v.14, n.3, p.1-17, set./dez. 2011.

RUFINO, Luiz Gustavo Bonatto; DARIDO, Suraya Cristina. Possíveis diálogos entre a educação física escolar e o conteúdo das lutas na perspectiva da cultura corporal. Conexões, v. 11, n. 1, p. 145-170, jan./mar. 2013.

SÓ, Marcos Roberto. Das relações com os saberes das lutas nas aulas de Educação Física: as perspectivas dos alunos. 2014. 199f. Dissertação (Mestrado em Educação) - Universidade Estadual Paulista, Presidente Prudente, 2014. 